\title{
Kanglaite inhibits EMT caused by TNF-a via NF-KB inhibition in colorectal cancer cells
}

\author{
Guiling Shi ${ }^{1, *}$, Xiaoli Zheng ${ }^{1, *}$, Shiwu Zhang ${ }^{1}$, Xiaojing Wu ${ }^{1}$, Fei Yu ${ }^{3}$, Yijia Wang ${ }^{1}$ \\ and Fei Xing ${ }^{2}$ \\ ${ }^{1}$ Tianjin Union Medical Center, Tianjin 300121, China \\ ${ }^{2}$ The Key Laboratory of Weak Light Nonlinear Photonics, Ministry of Education, Teda Applied Physics School and School of \\ Physics, Nankai University, Tianjin 300071, China \\ ${ }^{3}$ School of Pharmacy, Tianjin Medical University, Tianjin 300121, China \\ *These authors contributed equally to this work \\ Correspondence to: Yijia Wang, email: yijiawang_1980@163.com \\ Fei Xing, email: 370027468@qq.com
}

Keywords: TNF-a; EMT; kanglaite; NF-KB; colorectal cancer cell lines

Received: November 01,2017 Accepted: December 01,2017 Published: December 22, 2017

Copyright: Shi et al. This is an open-access article distributed under the terms of the Creative Commons Attribution License 3.0 (CC BY 3.0), which permits unrestricted use, distribution, and reproduction in any medium, provided the original author and source are credited.

\section{ABSTRACT}

Tumor necrosis factor-alpha is a critical pro-inflammatory cytokine produced by macrophages and was once considered an anti-tumor agent. However, a low dose of tumor necrosis factor-alpha can cause epithelial mesenchymal transition, angiogenesis and metastasis. NF-KB contributes to epithelial mesenchymal transition induced by tumor necrosis factor-alpha. Kanglaite, an extract from the Coix lacryma-jobi (adlay) seed, is an NF-KB inhibitor. The aim of this study was to investigate whether Kanglaite could inhibit epithelial mesenchymal transition caused by tumor necrosis factor-alpha using four colorectal cancer cell lines, HCT106, HCT116, LoVo and CT26. Our results showed that tumor necrosis factor-alpha -mediated activation of NF-kB, caused changes in epithelial mesenchymal transition -related protein expression, and increased migration and invasion in all four cell lines. However, these effects were inhibited by Kanglaite when used in combination with tumor necrosis factor-alpha. In a subcutaneous tumor model of CT26, tumor necrosis factor-alpha enhanced the tumorigenic ability of the cells, and again this was inhibited by Kanglaite. However, treatment with Kanglaite alone caused almost no inhibition of epithelial mesenchymal transition -mediated tumor growth, when cells were pretreated with tumor necrosis factor-alpha prior to injection. These results suggest that Kanglaite inhibits tumor necrosis factor-alpha -mediated epithelial mesenchymal transition in colorectal cancer cell lines via inhibition of NF-kB.

\section{INTRODUCTION}

Tumor necrosis factor-alpha (TNF- $\alpha)$ is a critical pro-inflammatory cytokine that has been shown to play an important role in many physiological and pathological processes, including immunity, cachexia, inflammatory reaction, and tumor progression [1]. As a multifunctional cytokine, TNF- $\alpha$ has a complex role in the treatment of cancer. High doses of TNF- $\alpha$ can inhibit tumor angiogenesis and induce apoptosis, but long-term treatment with low doses causes proliferation, invasion, angiogenesis and metastasis of tumor cells [2]. It is also worth mentioning that TNF- $\alpha$ may be related to cancer development and metastasis in certain tumor microenvironments [3].

Furthermore, as an endogenous tumor-promoting factor, TNF- $\alpha$ can also cause epithelial mesenchymal transition (EMT) in several types of cancer cells [4]. Overproduction of TNF- $\alpha$ alters the adhesive ability of tumor cells and enhances their metastatic potential. It has been confirmed that TNF- $\alpha$ expression levels have a positive correlation with Dukes' stages, and that TNF- $\alpha$ 
mRNA transcripts are higher in colorectal cancer (CRC) cells than normal epithelial colon cells [5]. This correlation between TNF- $\alpha$ and tumor grade is also seen in severe ovarian tumors [6].

TNF- $\alpha$ activates signaling pathways such as NF$\kappa \mathrm{B}$, which correlates with TNF- $\alpha$-mediated tumor cell invasion and migration [7]. Upon TNF- $\alpha$ stimulation, activated IKK $\beta$ phosphorylates I $\kappa \mathrm{B} \alpha$, an $\mathrm{NF}-\kappa \mathrm{B}$ inhibitor, then induces its degradation and triggers the liberation of $\mathrm{NF}-\kappa \mathrm{B}$. As a result, the NF- $\kappa \mathrm{B}$ heterodimer translocates to the nucleus and induces the expression of genes related to cell proliferation, cell survival, invasion, EMT, immune response and angiogenesis. Because $\mathrm{NF}-\kappa \mathrm{B}$ activation induces EMT [8], NF- $\mathrm{B}$ is a potential target to prevent tumor cell invasion and migration induced by some agents.

$\mathrm{NF}-\kappa \mathrm{B}$ is essential for TNF- $\alpha$-induced EMT [9]. Research has shown that the invasion and migration induced by TNF- $\alpha$ can be inhibited by drugs that inhibit NF- $\kappa \mathrm{B}$ activation. For example, vitamin D3 upregulates protein 1, which inhibits hepatocarcinogenesis by suppressing TNF- $\alpha$ induced NF- $\kappa \mathrm{B}$ activation [10]. Crebanine can also suppress invasion of human lung adenocarcinoma cells by blocking $\mathrm{NF}-\kappa \mathrm{B}-$ regulated gene products [11].

It has been reported that Kanglaite (KLT) inhibits NF- $\kappa B$ signaling $[12,13]$. KLT, a standardized, pharmaceutical-grade emulsion of Coix seed oil, has been approved by the Chinese Ministry of Public Health for several years based on its clinical evidence for broadspectrum anti-tumour activity [14-17]. KLT has been used in to treat over millions patients in China for treatment of various common types of cancer [18]. The main active ingredient of KLT is a triglyceride containing four types of fatty acids. Research has shown that KLT principally blocks cell cycle at G2/M phase to reduce cellular mitotic division and inhibit proliferation of tumour cells. KLT can also activate pro-apoptotic factors and lead cells to apoptosis [6]. It is known that KLT [13] or Coix seed extract [12] can inhibit NF- $\kappa \mathrm{B}$, but whether KLT inhibits EMT is still unclear. Therefore, we hypothesized that KLT may suppress the invasion and migration induced by TNF- $\alpha$ in cancer cells. Four CRC cell lines were used to investigate the potential inhibitory effect of KLT on TNF- $\alpha$ induced cell invasion and migration in colorectal cancer.

\section{RESULTS}

\section{Determination of suitable TNF- $\alpha$ and KLT concentrations}

The impact of TNF- $\alpha$ and KLT on cell viability was assessed using an MTT assay. Supplementary Figure 1 shows that TNF- $\alpha$ at concentrations above $20 \mathrm{ng} / \mathrm{ml}$ had a considerable inhibitory effect on cell viability. However, lower concentrations of TNF- $\alpha(<5 \mathrm{ng} / \mathrm{ml}$ for CT26, and $<10 \mathrm{ng} / \mathrm{ml}$ for the other three cell lines) did not exhibit obvious cytotoxic effects, even after a relatively long treatment time $(48 \mathrm{~h})$. Within the scope of concentrations used in this assay, KLT only had a low inhibitory effect. When TNF- $\alpha$ and KLT were used together, the cytotoxic effect of TNF- $\alpha$ was slightly enhanced by the presence of KLT. Therefore, for all subsequent experiments, a concentration of $10 \mathrm{ng} / \mathrm{ml}$ TNF- $\alpha$ and $2 \mu \mathrm{l} / \mathrm{ml} \mathrm{KLT}$ was used for the HCT106, HCT116 and LoVo cell lines, and $5 \mathrm{ng} / \mathrm{ml}$ TNF- $\alpha$ and $1 \mu \mathrm{l} / \mathrm{ml}$ KLT was used for the CT26 cells.

\section{KLT inhibits TNF- $\alpha$-induced NF- $\mathrm{NB}$ activation}

$\mathrm{NF}-\kappa \mathrm{B}$ is a key transcriptional regulator of extracellular proteases and pro-inflammatory cytokines that promote survival, invasion and adhesion of cancer cells $[18,19]$. NF- $\kappa \mathrm{B}$ activation also contributes to EMT, which is important for cancer dissemination [20]. NF- $\kappa B$ exists as a homodimer or as a heterodimer composed of two subunits, p50 and p65. The p50-p65 dimer maintains normal physiological function in vivo. Therefore, we used an anti-p65 antibody to identify NF- $\mathrm{B}$ activation. Normally, NF- $\kappa B$ is sequestered by members of the I $\kappa$ B family to form an inactivated compound in the cytoplasm. Stimulation of cells with TNF- $\alpha$ initiates a cascade of signaling events leading to $\mathrm{NF}-\kappa \mathrm{B}$ activation. After TNF- $\alpha$ binds to the TNF receptor, I $\kappa \mathrm{B}$ kinase (IKK) is activated, which causes $\mathrm{I} \kappa \mathrm{B}$ degradation. When $\mathrm{NF}-\kappa \mathrm{B}$ dissociates from $\mathrm{I} \kappa \mathrm{B}, \mathrm{NF}-\kappa \mathrm{B}$ is activated and transferred to the nucleus. IKK and $\mathrm{I} \kappa \mathrm{B}$ are both are cytoplasmic proteins; therefore, they can only be detected in cytosolic extractions [21].

Figure 1 and Supplementary Figure 2 show that TNF $-\alpha$ activated NF- $\kappa \mathrm{B}$, decreased $\mathrm{I} \kappa \mathrm{B}$ expression and upregulated IKK expression in all four CRC cell lines. These results are similar to published research $[9,11]$. KLT inhibited the effect of TNF- $\alpha$, but when KLT was used alone it had no significant effect on NF- $\mathrm{B}$, IKK or $\mathrm{I} \kappa \mathrm{B}$ expression.

\section{TNF- $\alpha$ increases EMT-related protein expression, which is inhibited by KLT}

$\mathrm{NF}-\kappa \mathrm{B}$ activation is a reciprocal response to various anti-tumor reagents [22], and TNF- $\alpha$ is no exception [23]. $\mathrm{NF}-\kappa \mathrm{B}$ upregulates proteins that promote tumor growth and proliferation, such as cyclin-D1, c-myc [23], MMP-9 [24]. TNF- $\alpha$ also potentiates EMT, for example by upregulating vimentin, stabilizing snail, or downregulating E-cadherin [25]. Our results (Figure 2 and Supplementary Figure 3) showed similar effects in that cyclin-D1, c-myc, MMP-9, vimentin and snail expression were all increased, while E-cadherin expression was decreased in the four CRC cell lines after treatment with TNF- $\alpha$. KLT treatment alone had no significant effect on the expression of these proteins. But when cells were treated simultaneously with TNF- $\alpha$ and KLT, KLT inhibited these changes in protein expression induced by TNF- $\alpha$. In addition, after $48 \mathrm{~h}$ treatment with 
TNF- $\alpha$ (Supplementary Figure 4), the HCT106, HCT116 and LoVo cells exhibited a change in morphology, from an epithelial morphology to a mesenchymal spindle-like shape, with fusiform features. The CT26 cells exhibited no obvious morphological changes, which may due to their already fibrous morphology. KLT was able to reverse these morphological changes when combined with TNF- $\alpha$.

\section{KLT inhibits the migration and invasion of CRC cells promoted by TNF- $\alpha$}

It has been reported that TNF- $\alpha$ can enhance the migration and invasion abilities of cancer cells [25]. To investigate whether KLT exerts a regulatory effect on cell migration and invasion induced by TNF- $\alpha$, wound healing scratch and transwell invasion assays were performed. As shown in Figure 3, the four CRC cell lines exhibited significantly enhanced migration at $48 \mathrm{~h}$ after TNF- $\alpha$ treatment. When cells were treated simultaneously with TNF- $\alpha$ and KLT, this enhancement effect was inhibited. As shown in Figure 4, the transwell invasion assay also revealed that TNF- $\alpha$ promoted the invasive ability of these cells, while KLT inhibited this effect. In addition, treatment with KLT alone had a slight inhibitory effect on cell migration and invasion.

\section{TNF- $\alpha$ enhances the tumorigenic ability of CT26 cells, while KLT inhibits it in vivo}

Compared with tumors acquired from tumorbearing mice, it was found that KLT treatment inhibited the tumorigenic ability of CT26 cells (Figure 5). Briefly, in mice that did not receive a KLT injection, the TNF- $\alpha$ pretreated group developed the largest tumors, which may due to EMT caused by TNF- $\alpha$. Tumor volume in the TNF- $\alpha+$ KLT group was reduced, suggesting that KLT offsets part of TNF- $\alpha$ effect. A single KLT pretreatment also exhibited some inhibition of tumorigenic ability. On the other hand, tumor growth was slightly reduced in the KLT injected mice, but KLT had only a mild inhibitory effect on TNF- $\alpha$-induced EMT.

\section{DISCUSSION}

Many epithelial tumors undergo EMT, which facilitates their invasion. Longterm treatment with antitumor drugs, such as paclitaxel [26] and cisplatin [27], causes tumor resistance and EMT, but some agents can reverse the EMT induced by anti-tumor drugs [26, 27]. It has been shown that NF- $\kappa$ B activation is one response of tumor cells to some drugs, and that it contributes to EMT $[8,28]$. TNF- $\alpha$ induces EMT via many signal pathways, including NF- $\kappa \mathrm{B}$ [9], and our results showed that KLT, an $\mathrm{NF}-\kappa \mathrm{B}$ inhibitor, was able to inhibit the EMT induced by TNF- $\alpha$.

As an anti-tumor agent, TNF- $\alpha$ induces cancer cell death, and KLT also has anti-tumor effects. Therefore, we used an MTT assay to determine suitable concentrations for TNF- $\alpha$ and KLT treatment to obtain an inhibition rate of about $10 \%$ after $48 \mathrm{~h}$. Low levels of cytotoxicity using these combined drugs facilitated the analysis EMT in four CRC cell lines in subsequent experiments.
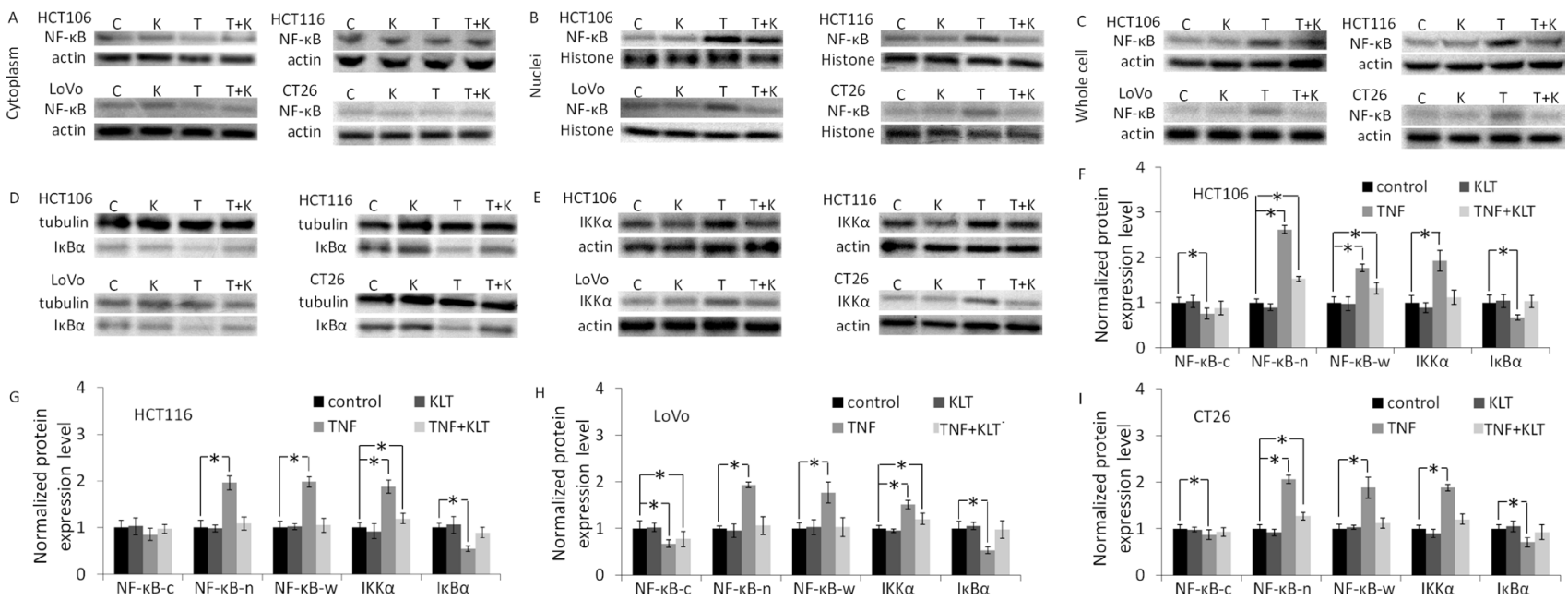

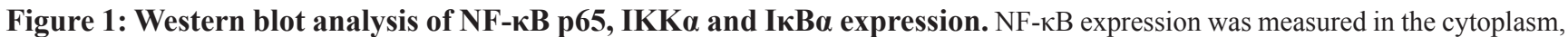
nuclei and whole cell lysate in order to determine whether NF- $\kappa \mathrm{B}$ is translocated to the nucleus induced by TNF- $\alpha$. Because IKK and $\mathrm{I} \kappa \mathrm{B}$ are both cytoplasmic proteins, and also interact with NF- $\kappa \mathrm{B}$ in the cytoplasm, these proteins could only be detected in the cytoplasmic samples. In blot images, $\mathrm{C}$ represents control, K represents KLT only, T represents TNF- $\alpha$ only and T+K represents TNF- $\alpha$ plus KLT. Experiments were performed in triplicate. (A) NF- $\kappa$ B p65 expression in the cytoplasm. (B) NF- $\mathrm{BB}$ p65 expression in the nuclei.

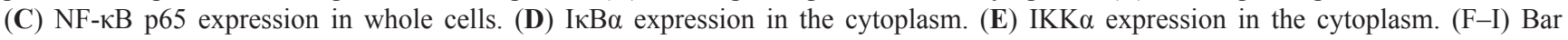
diagrams of densitometric analysis of NF- $\kappa \mathrm{B}, \mathrm{IKK} \alpha$ and $\mathrm{I} \kappa \mathrm{B} \alpha$ expression in the four CRC cell lines. NF- $\mathrm{B}$-c represents NF- $\kappa \mathrm{B}$ expression

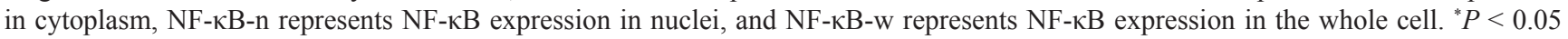
indicates a significant difference compared to the control group. Full length blots of A-E are shown in Supplementary Figure 5. 
EMT can be triggered by signals from the tumor microenvironment. TNF- $\alpha$ is produced by macrophages and activates inflammatory processes during tumor promotion [29]. NF- $\kappa \mathrm{B}$ is downstream of TNF- $\alpha$ and other inflammatory cytokines produced in the tumor microenvironment, and is a major mediator of the tumorpromoting activity of inflammatory cytokines [30]. NF$\kappa \mathrm{B}$ signaling is related to TNF- $\alpha$-induced EMT [7, 9]. Therefore, if an agent inhibits NF- $\kappa \mathrm{B}$ signaling, it may also inhibit the invasion and migration that was induced by TNF- $\alpha$. Previous research showed that KLT inhibits NF$\kappa \mathrm{B}$ activation $[12,13]$, and our results also showed that TNF- $\alpha$ activated NF- $\kappa \mathrm{B}$ in four CRC cell lines, whereas KLT inhibited NF- $\kappa$ B. We found that KLT upregulated IKK $\alpha$ at TNF- $\alpha$ treated cells, which suggested that KLT may inhibit NF- $\kappa \mathrm{B}$ activation on blocking upstream proteins, for example, PI3K/Akt or TNF receptor, but the mechanism of how KLT inhibits on these proteins remains to be further investigated. Several EMT-related proteins were measured and were found to be upregulated

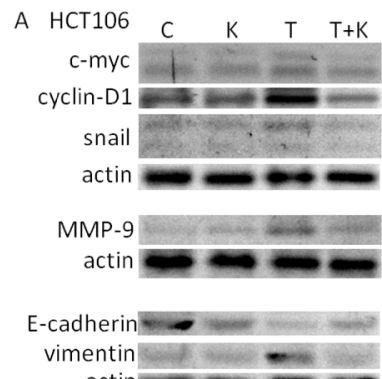

actin $=0$
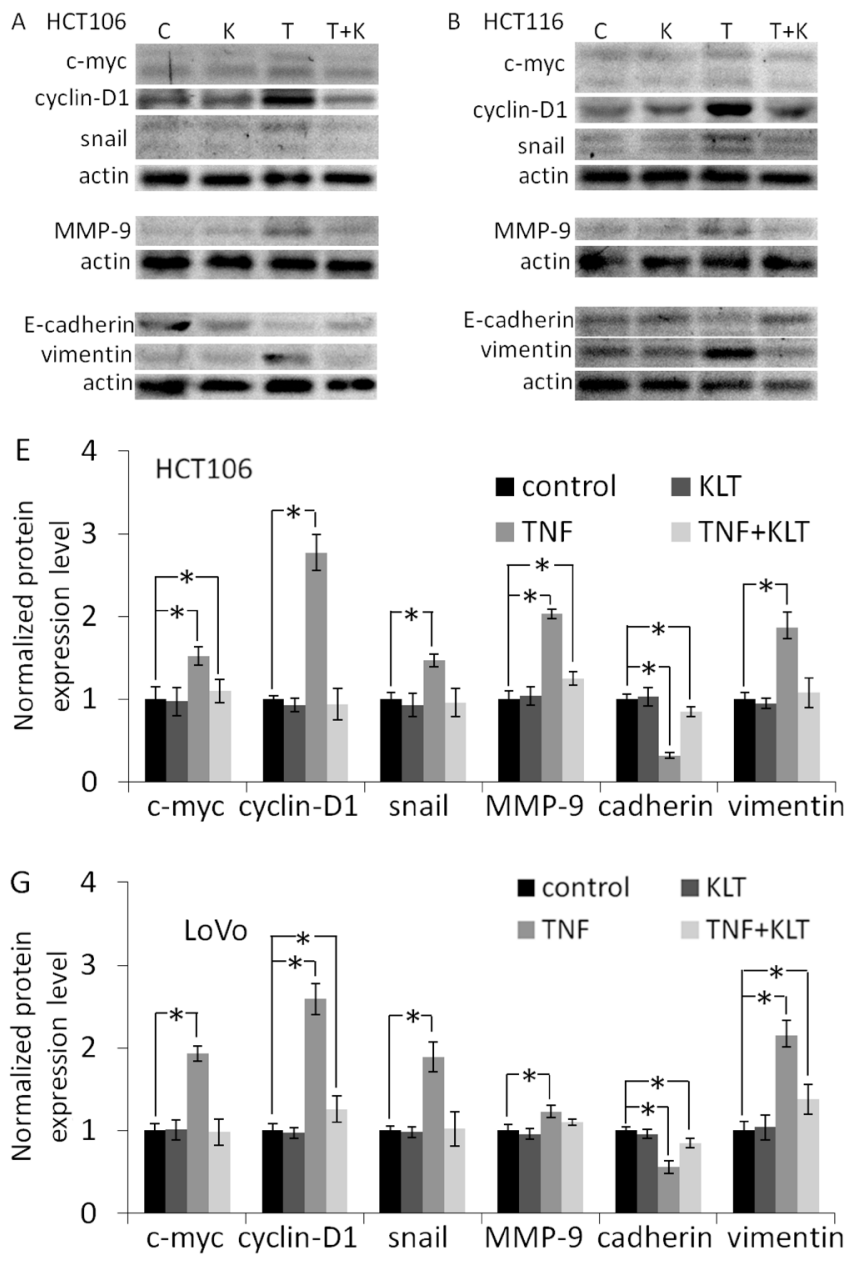

by TNF- $\alpha$, whereas KLT was shown to partially offset the effects of TNF- $\alpha$. The wound healing scratch and cell invasion assays confirmed that TNF- $\alpha$ increased the migration and invasion ability of the cells, and that this was offset by KLT. Treatment with KLT only had almost no effect on migration, but did have some inhibitory effect on the invasion of HCT106 and HCT116 cells, but not LoVo and CT26 cells. These variable results could due to the low concentration of KLT, as different cells do not have the same sensitivity to KLT.

Unlike the other three CRC cell lines that have an epithelioid morphology, CT26 cells exhibit a fibrous morphology, but nonetheless are commonly used to research EMT in vitro and in vivo [31]. Our MTT assay showed that TNF- $\alpha$ is more cytotoxic in CT26 than in other cells, but that CT26 also exhibited variable changes in EMT-related protein expression at lower concentrations of TNF- $\alpha$ treatment. Our subcutaneous tumor model showed that CT26 cells with a more EMT-like phenotype had more tumorigenic ability, and that the tumor volume

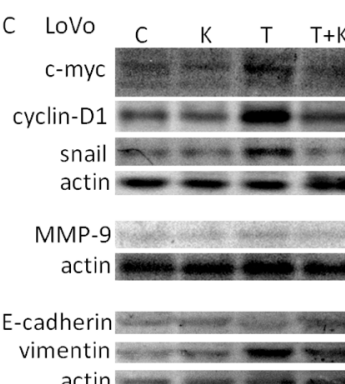

$\operatorname{actin} m-\infty+\infty$
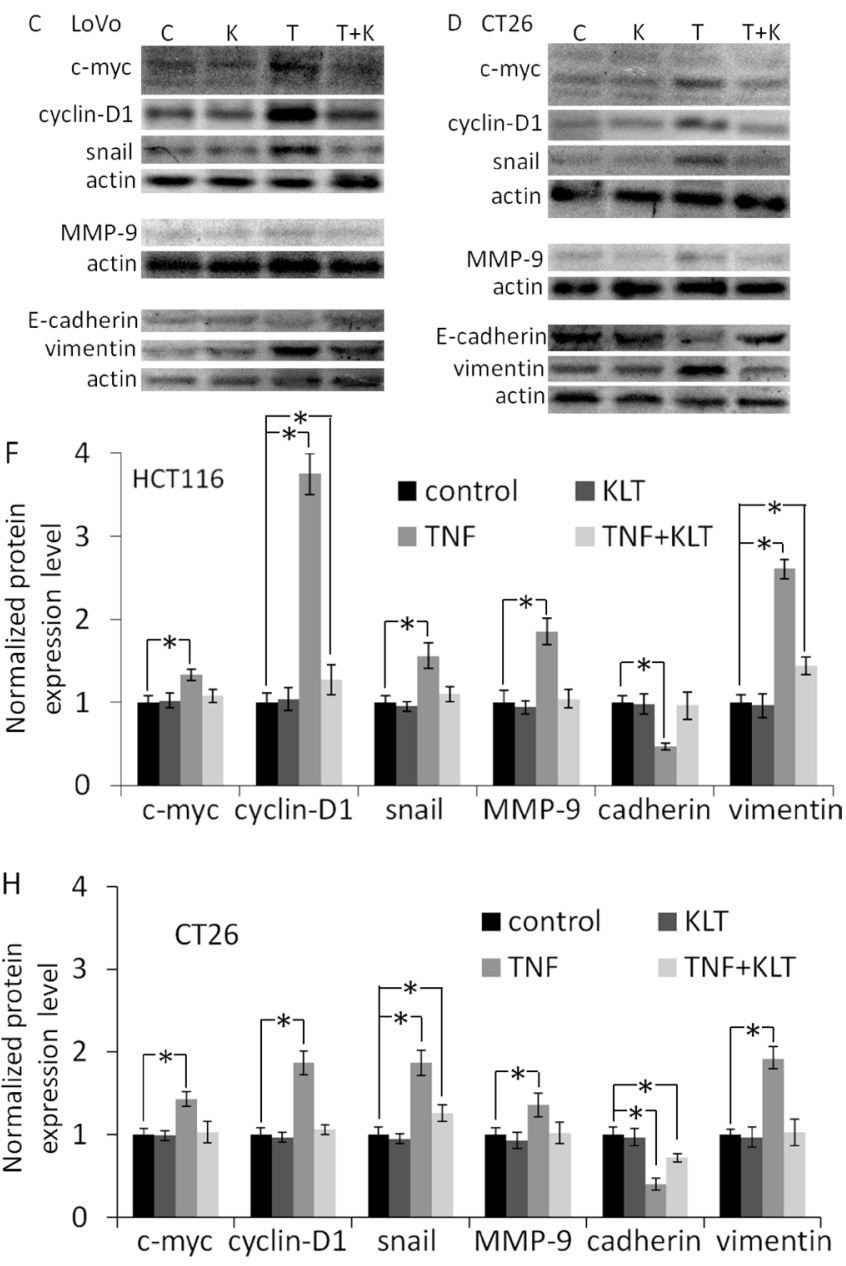

Figure 2: Western blot analysis of c-myc, cyclin-D1, snail, MMP-9, E-cadherin and vimentin expression. Experiments were performed in triplicate. (A-D) Protein expression in the four CRC cell lines after treatment with different reagents, as indicated. $\mathrm{C}$ represents control, K represents KLT only, T represents TNF- $\alpha$ only, and T+K represents TNF- $\alpha$ plus KLT. (E-H) Bar diagrams of densitometric analysis of data in panels A-D. ${ }^{*} P<0.05$ indicates a significant difference compared to the control group. Full length blots of A-D are shown in Supplementary Figure 6. 
decreased significantly after an intraperitoneal injection of KLT. The wound healing scratch and cell invasion assays showed that KLT had almost no effect on the migration and invasion abilities of CT26 cells in vitro, which could be due to the low concentration of KLT that was used to treat the cells. The KLT concentration used in our in vitro experiments was relatively low [32] in order to avoid significant cytotoxicity, because the NF- $\kappa \mathrm{B}$ inhibitor may sensitize cells to TNF- $\alpha$ [33]. Intraperitoneal injections of a higher concentration of KLT were used to inhibit tumor growth in vivo, according to a previous report [13] and our preliminary experiments. At this concentration, KLT exhibited an inhibitory effect on tumor growth in vivo, which suggests that KLT has a mild effect on tumors with
EMT in vivo. Thus, KLT may have a preventive effect on EMT development but does not inhibit EMT tumor formation.

\section{CONCLUSIONS}

The present work investigated the inhibitory effect of KLT on TNF- $\alpha$-induced EMT. Four CRC cell lines, HCT106, HCT116, LoVo and CT26, were used in both in vitro and in vivo experiments. Our results showed that TNF- $\alpha$ activated NF- $\kappa$ B and induced EMT in all four of the cell lines. When cells were treated with a combination of TNF- $\alpha$ and KLT, the NF- $\kappa$ B activation was inhibited, EMT-related protein expression was decreased, and the
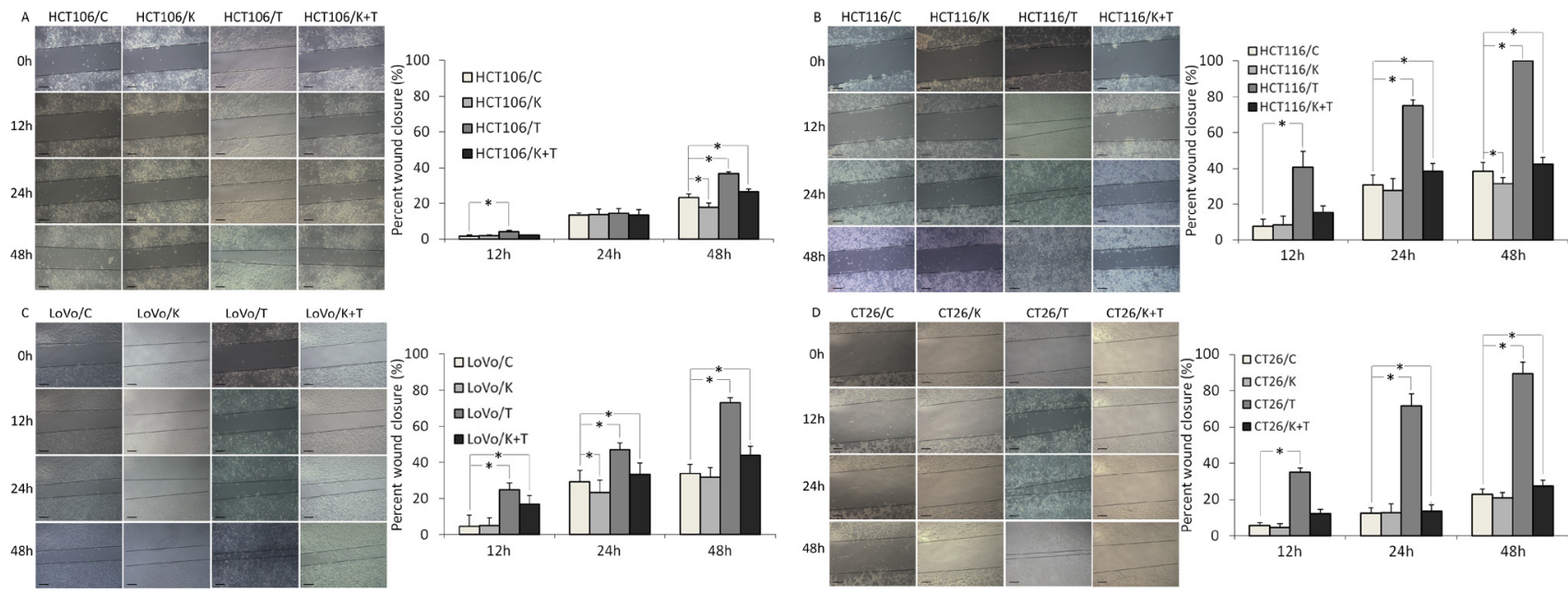

Figure 3: Migration of the four CRC cell lines after KLT and TNF- $\alpha$ treatment was measured using a wound healing scratch assay (original magnification $\times \mathbf{1 0 0}$ ). $\mathrm{C}$ represents control, $\mathrm{K}$ represents KLT only, $\mathrm{T}$ represents $\mathrm{TNF}-\alpha$ only, and $\mathrm{T}+\mathrm{K}$ represents TNF- $\alpha$ plus KLT. The scale bars represent $100 \mu \mathrm{m}$. Experiments were performed in triplicate. ${ }^{*} P<0.05$ indicates a significant difference compared to the control group. Furthermore, for all cell lines, the percent wound closure in the $\mathrm{K}+\mathrm{T}$ group was significantly lower than for the $\mathrm{T}$ group $(P<0.05)$.

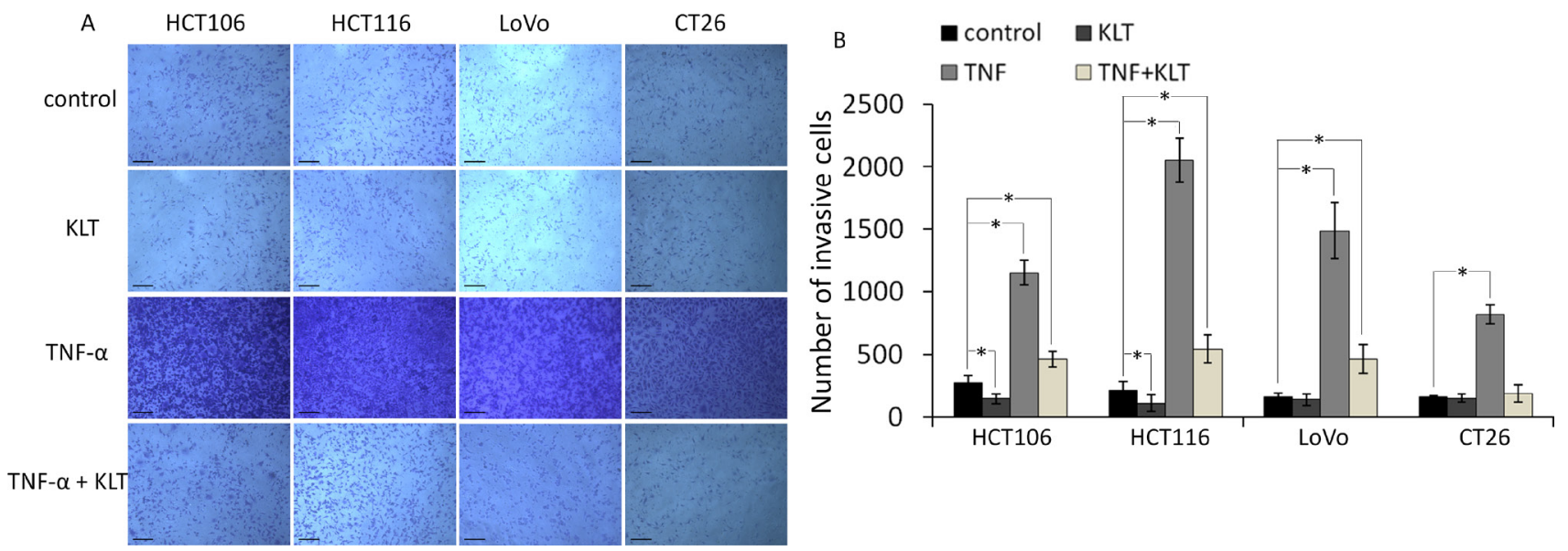

Figure 4: Invasion of the four CRC cell lines after KLT and TNF- $\alpha$ treatment was measured using a transwell assay (original magnification $\times \mathbf{1 0 0}$ ). The scale bars represent $100 \mu \mathrm{m}$. Experiments were performed in triplicate. ${ }^{*} P<0.05$ indicates a significant difference compared to the control group. For all cells lines, invasion cell numbers were significantly lower in the TNF+KLT group than in the TNF group $(P<0.05)$. 
migration and invasion effects caused by TNF- $\alpha$ were accentuated. However, when the cells were treated with KLT alone, these effects were mild. A Balb/c mouse model was used to determine the tumorigenic ability of CT26 cells in combination with different agents and we drew the same conclusions. Furthermore, KLT had an inhibitory effect on tumor growth in vivo, but also had a slight inhibitory effect on tumors derived from the TNF- $\alpha$ group, suggesting that KLT is not effective against EMT tumors. In summary, our data suggest that KLT prevents EMT caused by TNF- $\alpha$ via inhibition of NF- $\kappa$ B signaling.

\section{MATERIALS AND METHODS}

\section{Reagents and antibodies}

All cell culture media, antibiotics, and trypsin were purchased from Gibco (Grand Island, NY, USA), and fetal bovine serum (FBS) was purchased from HyClone (Logan, UT, USA). Mouse anti-E-cadherin antibody, mouse antiNF- $\kappa$ B p65 antibody, mouse anti-cyclin D1 antibody, mouse anti-c-myc antibody, and mouse anti-snail antibody were purchased from Santa Cruz Biotechnology (CA, USA). Rabbit anti-matrix metalloproteinase-9 (MMP-9) antibody, rabbit anti-IKK $\alpha$ antibody, rabbit anti-I $\kappa \mathrm{B} \alpha$ antibody, rabbit anti-vimentin antibody, rabbit anti-Histone H3 antibody, mouse anti- $\beta$-tubulin antibody, goat antirabbit IgG-peroxidase, goat anti-mouse IgG-peroxidase, goat anti-mouse IgG FITC, goat anti-rabbit IgG FITC, goat anti-mouse IgG TRITC, DAPI and methyl thiazolyl tetrazolium (MTT), were purchased from Sigma-Aldrich (St. Louis, MO, USA). Immobilon membranes were purchased from Merck Millipore (Bedford, MA, USA). ECL Plus substrate, bicinchoninic acid reagents, and RIPA lysis buffer were purchased from CWBio (Beijing, China). TNF- $\alpha$ was purchased from Sino biological Inc. (Beijing, China). KLT injection was purchased from Zhejiang Kanglaite Pharmaceutical Co., Ltd, (Zhejiang, China). Nuclear and cytoplasmic protein extraction kit, crystal violet were purchased from Beyotime (Shanghai, China).

\section{Cell lines}

HCT106, HCT116, LoVo, and CT26 cell lines were purchased from the Shanghai Institutes for Biological Sciences, Chinese Academy of Sciences. HCT106, HCT116, and LoVo cell lines are human CRC cell lines. CT26 is a murine colon adenocarcinoma cell line derived

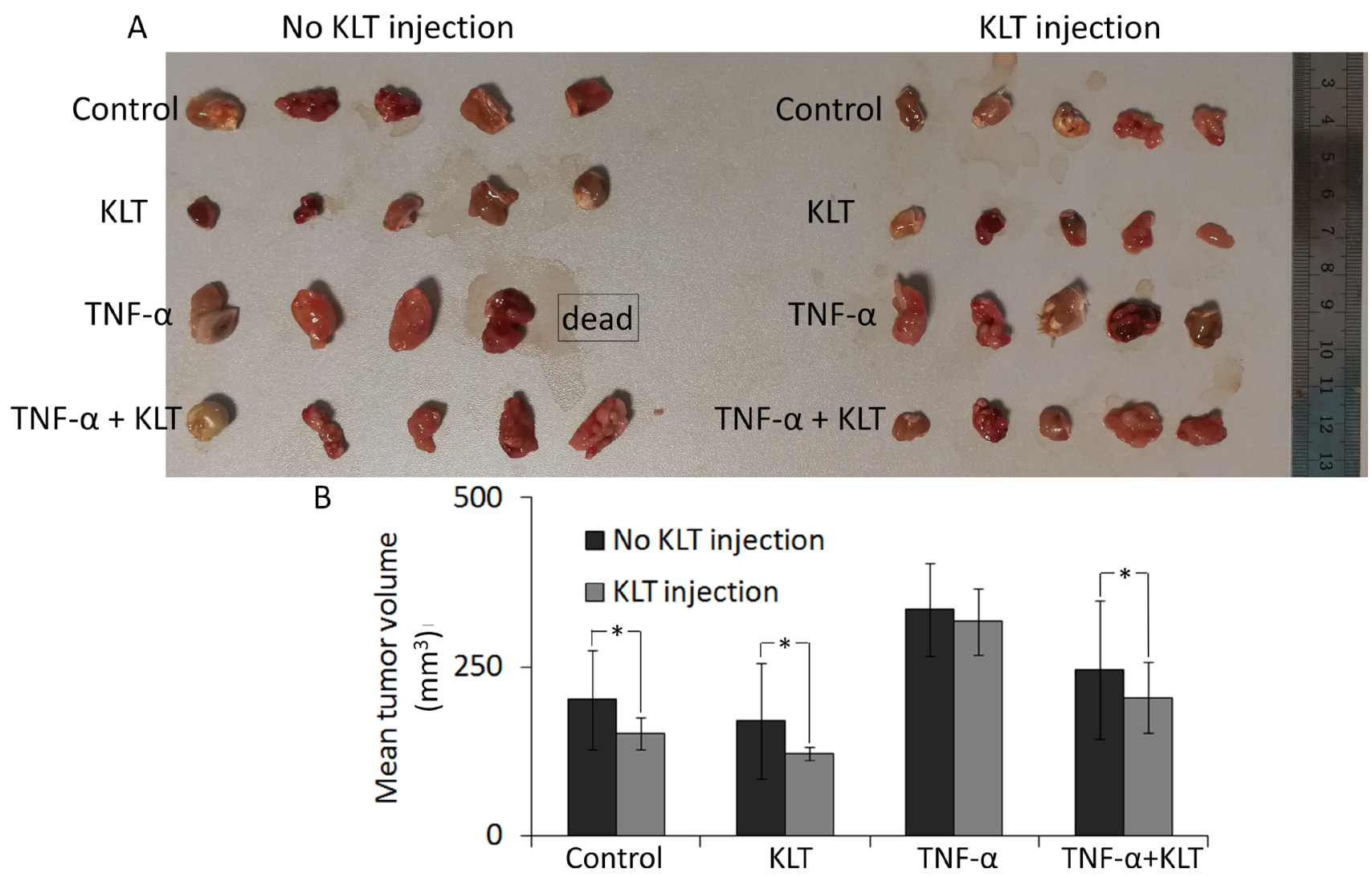

Figure 5: Inhibition of tumor growth by KLT. (A) Four different pretreatment strategies of CT26 cells used for subcutaneous inoculation. Each group contained five mice. Tumors were allowed to develop for 15 days, but one mouse from the TNF- $\alpha$ pretreated $\&$ no KLT injection group was found dead at 14 days. (B) Columns represent mean volume from 5 tumors, except for the TNF- $\alpha$ pretreated $\&$ no KLT injection data, which came from 4 tumors. Average tumor volumes in two adjacent columns were compared using the Student's $t$-test. ${ }^{*} P<0.05$ represents a significant difference. 
from N-nitroso-N-methylurethane treated Balb/c mice. All cells were cultured in RPMI 1640 medium supplemented with $10 \% \mathrm{FBS}, 100 \mu \mathrm{g} / \mathrm{ml}$ streptomycin and $100 \mathrm{U} / \mathrm{ml}$ penicillin.

\section{TNF- $\alpha$ and KLT treatment}

The four cell lines were treated with different concentrations of TNF- $\alpha$ and KLT in order to identify a suitable concentration that caused no significant cytotoxicity. Four treatment groups were used: (1) Cells without drug treatment served as the control group; (2) Cells treated with KLT alone for 48 h; (3) Cells treated with TNF- $\alpha$ alone for $48 \mathrm{~h}$; (4) Cells treated with a mixture of TNF- $\alpha$ and KLT for 48 h. Cell viability was measured using an MTT assay. The rate of cell growth inhibition in each well was calculated by defining the absorption of the control group as $100 \%$. Measurements were performed in triplicate. Cells from all four groups were used for western blot, immunocytochemistry, the wound healing scratch assay and the cell invasion assay.

\section{Western blot analysis}

Cells from all four experimental groups were trypsinized and used to generate protein samples to detect $\mathrm{NF}-\kappa \mathrm{B}, \mathrm{IKK} \alpha, \mathrm{I} \kappa \mathrm{B} \alpha$, E-cadherin, vimentin, MMP-9, snail, cyclin D1 and c-myc expression.

To detect NF- $\kappa \mathrm{B}, \mathrm{I} \kappa \mathrm{B} \alpha$ and IKK $\alpha$ expression, nuclear and cytosolic proteins were separated from the harvested cells using a nuclear and cytoplasmic protein extraction kit (Beyotime, Shanghai, China) according to manufacturer's instructions. Briefly, $200 \mu$ cytosolic protein extraction agent A with $1 \mathrm{mM}$ phenylmethyl sulfonylfluoride (PMSF) was added to $20 \mu \mathrm{l}$ harvested cells at $4^{\circ} \mathrm{C}$. The mixture was incubated on ice for $15 \mathrm{~min}$ then $10 \mu \mathrm{l}$ cytosolic protein extraction agent $\mathrm{B}$ was added. Tubes were vortexed vigorously for $5 \mathrm{~s}$ then incubated on ice for $1 \mathrm{~min}$. After $5 \mathrm{~s}$ vigorous vortexing, tubes were centrifuged at $15,000 \times g$ for $5 \mathrm{~min}$ at $4^{\circ} \mathrm{C}$. The supernatant, containing the cytoplasmic fraction, was transferred to a fresh tube. The insoluble pellet, containing the nuclear fraction, was resuspended in nuclear protein extraction agent (50 $\mu \mathrm{l})$ with $1 \mathrm{mM}$ PMSF, vortexed vigorously for $20 \mathrm{~s}$ and incubated on ice for $30 \mathrm{~min}$. During this incubation, tubes were vortexed for $15 \mathrm{~s}$ every $5 \mathrm{~min}$, for six times in total. Tubes were then centrifuged at $15,000 \times g$ for $10 \mathrm{~min}$ at $4^{\circ} \mathrm{C}$. The supernatant, containing the nuclear fraction, was transferred to a fresh tube.

To detect other proteins (E-cadherin, vimentin, MMP-9, snail, cyclin D1 and c-myc), $1 \times 10^{6}$ cells were lysed with $500 \mathrm{ml}$ RIPA lysis buffer containing a protein inhibitor for 20 minutes on ice. Cell lysates were centrifuged and supernatants, containing proteins, were transferred to fresh tubes.
Protein samples were quantitated using bicinchoninic acid reagents, resuspended in SDS-loading buffer and boiled. Protein $(10 \mu \mathrm{g})$ was run on an SDS-PAGE gel and transferred to an Immobilon membrane using a semi-dry blotting method. The membrane was probed successively with appropriate primary and secondary antibodies using standard techniques. Finally, signals were visualized by ECL and membranes were exposed to film. Each assay was performed in triplicate. Expression levels were quantified using Quantity One software (Bio-Rad Laboratories, Inc., Hercules, CA, USA) and normalized against $\beta$-actin, $\beta$-tubulin or Histone $\mathrm{H} 3$, respectively.

\section{Immunocytochemistry analysis}

Immunofluorescence staining was used to detect $\mathrm{NF}-\kappa \mathrm{B}, \mathrm{E}-\mathrm{cadherin}$ and vimentin expression. Briefly, cells were washed gently with PBS to remove culture medium, fixed with $10 \%$ formalin at room temperature for 15 minutes, treated with $0.5 \%$ Triton $\mathrm{X}-100$ for $5 \mathrm{~min}$ at $4{ }^{\circ} \mathrm{C}$, then blocked overnight with $5 \%$ normal goat serum $4^{\circ} \mathrm{C}$. Slides were washed with PBS and incubated with primary antibody for $1 \mathrm{~h}$ at $37^{\circ} \mathrm{C}$. For NF- $\kappa \mathrm{B}$ detection, slides were incubated with a mouse anti-NF- $\kappa \mathrm{B}$ antibody. For E-cadherin and vimentin, slides were incubated simultaneously with mouse anti-E-cadherin and rabbit anti-vimentin antibodies. After washing with PBS, slides were incubated with a FITC- or/and TRITC-conjugated secondary antibody and DAPI for $1 \mathrm{~h}$ at $37^{\circ} \mathrm{C}$. Finally, slides were washed with PBS and sealed. Coverslips were photographed immediately using an Olympus fluorescence microscope (Olympus, Japan).

\section{Wound healing scratch assay}

Cells were cultured in 6-well plates until they formed a monolayer, then serum-starved overnight. An artificial scratch wound was created using a $10 \mu \mathrm{l}$ pipette tip. The plate was washed with PBS to remove cell debris, then TNF- $\alpha$ and/or KLT was added to the cultures. Cells were maintained in serum-free culture medium at $37^{\circ} \mathrm{C}$, in $5 \% \mathrm{CO}_{2}$. Images of migration were captured at $0,12,24$ and $48 \mathrm{~h}$ after scratching. Experiments were repeated independently in triplicate. The following equation was used to calculate percent wound closure: percent wound closure $(\%)=[1-(\mathrm{Lt} / \mathrm{L} 0)] \times 100 \%$, where Lt represents width of scratch at time $t$ and L0 represents initial width of scratch.

\section{Cell invasion assay}

Cell invasion assays were performed using 24-well Matrigel-coated chambers $(6.5 \mathrm{~mm}$ in diameter, $8 \mu \mathrm{m}$ pore-size, $100 \mu \mathrm{g} / \mathrm{cm}^{2}$ Matrigel, Corning) according to the manufacturer's instructions. Briefly, cells were allowed to grow to subconfluency then serum-starved for $24 \mathrm{~h}$. Precoated chambers were rehydrated, then cells were 
trypsinized and placed onto the upper transwell chamber $\left(2 \times 10^{5}\right.$ cells per well) with $500 \mu \mathrm{l}$ serum-free medium, with or without KLT/TNF- $\alpha$. Medium $(750 \mu \mathrm{l})$ containing $10 \%$ FBS was placed into the lower chamber. All conditions were repeated in triplicate. After $24 \mathrm{~h}$ incubation at $37^{\circ} \mathrm{C}$ in $5 \% \mathrm{CO}_{2}$, cells that had not migrated were removed using a cotton swab, and cells that had migrated were fixed with $4 \%$ paraformaldehyde and stained with $0.1 \%$ crystal violet for $30 \mathrm{~min}$. Images of three different fields were captured from each membrane.

\section{Subcutaneous tumor model}

A subcutaneous tumor model was used to evaluate the tumorigenic ability of the CT26 cell line after treatment with different combinations of agents. The inhibitory effect of KLT on these tumors in vivo was also determined after intraperitoneal injection of KLT. Briefly, CT26 cells were treated with TNF- $\alpha$ and/or KLT for $48 \mathrm{~h}$, at a concentration determined as described in section 3.1. Each group comprised 5 mice. Treated cells were trypsinized and approximately $1 \times 10^{6}$ cells were injected subcutaneously into the flank of the mice (Sixweek-old, Balb/c, females). An intraperitoneal injection of $6.25 \mu \mathrm{l} / \mathrm{g}$ KLT [13] was administered every day. Mice were sacrificed 15 days after cell implantation. Tumors were removed and size was measured using calipers. Tumor volume $=\mathrm{L} \times \mathrm{S}^{2} / 2$, where " $\mathrm{L}$ " represents the larger diameter and " $\mathrm{S}$ " represents the smaller diameter. All animal experiments complied with the National Institutes of Health guide for the care and use of Laboratory animals (NIH Publications No. 8023, revised 1978).

\section{Statistical analysis}

All data represent mean \pm standard deviation. Statistical analysis was performed by Student's $t$-test using SPSS software. A $P$ value $<0.05$ was considered statistically significant.

\section{Abbreviations}

Tumor necrosis factor-alpha (TNF- $\alpha$ ), epithelial mesenchymal transition (EMT), colorectal cancer (CRC), Kanglaite (KLT), fetal bovine serum (FBS), matrix metalloproteinase-9 (MMP-9), methyl thiazolyl tetrazolium (MTT).

\section{Author contributions}

Conceived and designed the experiment: Yijia Wang and Guiling Shi. Performed the experiments: Yijia Wang, Guiling Shi, Shiwu Zhang, Xiaojing Wu, Yu Fei and Fei Xing. Wrote paper: Yijia Wang and Fei Xing. Reviewed the manuscript: Yijia Wang and Shiwu Zhang.

\section{ACKNOWLEDGMENTS AND GRANT SUPPORT}

This work was partially supported by the National Basic Research Program of China Grant number 2016YFC0102404, and the Natural Science Foundation of China (Grant No. 81472729, 81672426, 61505109, 61505109 and 61377052), and the Foundation of Tianjin Union Medical Center under Grant numbers 2016YJ033, and Science and Technology Fund of Tianjin Municipal Health Bureau under grand number 2015KY30.

\section{CONFLICTS OF INTEREST}

None.

\section{REFERENCES}

1. Wajant H, Pfizenmaier K, Scheurich P. Tumor necrosis factor signaling. Cell Death Differ. 2003; 10:45-65.

2. Wang X, Lin Y. Tumor necrosis factor and cancer, buddies or foes?. Acta Pharmacol Sin. 2008; 29:1275-1288.

3. Balkwill F. Tumor necrosis factor or tumor promoting factor?, Cytokine Growth Factor Rev. 2002; 13:135-141.

4. Soria G, Ofri-Shahak M, Haas I, Yaal-Hahoshen N, LeiderTrejo L, Leibovich-Rivkin T, Weitzenfeld P, Meshel T, Shabtai E, Gutman M, Ben-Baruch A. Inflammatory mediators in breast cancer: coordinated expression of TNF $\alpha$ $\&$ IL-1 $\beta$ with CCL2 \& CCL5 and effects on epithelialto-mesenchymal transition. BMC Cancer. 2011; 11:130. https://doi.org/10.1186/1471-2407-11-130.

5. Csiszár A, Szentes T, Haraszti B, Zou W, Emilie D, Petrányi G, Pócsik E. Characterisation of cytokine mRNA expression in tumour-infiltrating mononuclear cells and tumour cells freshly isolated from human colorectal carcinomas. Eur Cytokine Netw. 2001; 12:87-96.

6. Naylor MS, Stamp GW, Foulkes WD, Eccles D, Balkwill FR. Tumor necrosis factor and its receptors in human ovarian cancer. Potential role in disease progression. J Clin Invest. 1993; 91:2194-2206.

7. Wu Y, Zhou BP. TNF-alpha/NF-kappaB/Snail pathway in cancer cell migration and invasion. Br J Cancer. 2010; 102:639-644.

8. Julien S, Puig I, Caretti E, Bonaventure J, Nelles L, van Roy F, Dargemont C, de Herreros AG, Bellacosa A, Larue L. Activation of NF-kappaB by Akt upregulates Snail expression and induces epithelium mesenchyme transition. Oncogene. 2007; 26:7445-7456.

9. Li CW, Xia W, Huo L, Lim SO, Wu Y, Hsu JL, Chao CH, Yamaguchi H, Yang NK, Ding Q, Wang Y, Lai YJ, LaBaff $\mathrm{AM}$, et al. Epithelial-mesenchymal transition induced by $\mathrm{TNF}-\alpha$ requires $\mathrm{NF}-\kappa \mathrm{B}-$ mediated transcriptional upregulation of Twist1. Cancer Res. 2012; 72:1290-300. 
10. Kwon HJ, Won YS, Suh HW, Jeon JH, Shao Y, Yoon SR, Chung JW, Kim TD, Kim HM, Nam KH, Yoon WK, Kim DG, Kim JH, et al. Vitamin D3 upregulated protein 1 suppresses TNF- $\alpha$-induced NF- $\kappa \mathrm{B}$ activation in hepatocarcinogenesis. J Immunol. 2010; 185:3980-89.

11. Yodkeeree S, Pompimon W, Limtrakul P. Crebanine, an aporphine alkaloid, sensitizes TNF- $\alpha$-induced apoptosis and suppressed invasion of human lung adenocarcinoma cells A549 by blocking NF- $\kappa$ B-regulated gene products. Tumour Biol. 2014; 35:8615-24.

12. Woo JH, Li D, Wilsbach K, Orita H, Coulter J, Tully E, Kwon TK, Xu S, Gabrielson E. Coix seed extract, a commonly used treatment for cancer in China, inhibits NFkappaB and protein kinase $\mathrm{C}$ signaling. Cancer Biol Ther. 2007; 6:2005-11.

13. Pan P, Wu Y, Guo ZY, Wang R, Wang YJ, Yuan YF. Antitumor activity and immunomodulatory effects of the intraperitoneal administration of Kanglaite in vivo in Lewis lung carcinoma. J Ethnopharmacol. 2012; 143:680-685.

14. Wu P, Fang Y, Wang L. Combination of Kanglaite Injection with chemotherapy for treatment of advanced nonsmall cell lung cancer. Modern Oncology. 2004; 12:60-61.

15. Chen M, Nie L, Que C, Zhang W. Clinical observations on therapeutic effect of a combined therapy of kanglaite injection and chemotherapy in treating non-small cell lung cancer. Journal of Tumor's Prevention and Treatment. 2001; 8:394-395.

16. Li Y, Sun X, Zhang J, Yang D. Clinical observations on combination of Kanglaite with CEP for treatment of nonsmall cell lung cancer. China J Cancer Prev Treat. 2003; 10:895.

17. Lu Y, Li CS, Dong Q. Chinese herb related molecules of cancer-cell-apoptosis: a minireview of progress between Kanglaite injection and related genes. J Exp Clin. Cancer Res. 2008; 27:31-35.

18. Ramudo L, Yubero S, Manso MA, Vicente S, De Dios I. Signal transduction of MCP-1 expression induced by pancreatitis-associated ascitic fluid in pancreatic acinar cells. J Cell Mol Med. 2009; 13:1314-1320.

19. Sutcliffe AM, Clarke DL, Bradbury DA, Corbett LM, Patel JA, Knox AJ. Transcriptional regulation of monocyte chemotactic protein-1 release by endothelin-1 in human airway smooth muscle cells involves NF-kappaB and AP-1. Br J Pharmacol. 2009; 157:436-450.

20. Zhang Q, Helfand BT, Jang TL, Zhu LJ, Chen L, Yang XJ, Kozlowski J, Smith N, Kundu SD, Yang G, Raji AA, Javonovic B, Pins M, et al. Nuclear factor-kappaB-mediated transforming growth factor-beta-induced expression of vimentin is an independent predictor of biochemical recurrence after radical prostatectomy. Clin Cancer Res. 2009; 15:3557-67.

21. Hayden MS, Ghosh S. Signaling to NF-kappaB. Genes Dev. 2004; 18:2195-224.

22. Huang Y, Fan W. IkappaB kinase activation is involved in regulation of paclitaxel-induced apoptosis in human tumor cell lines. Mol Pharmacol. 2002; 61:105-13.

23. Vaiopoulos AG, Athanasoula KC, Papavassiliou AG. NF-кB in colorectal cancer. J Mol Med (Berl). 2013; 91:1029-37.

24. Dilshara MG, Kang CH, Choi YH, Kim GY. Mangiferin inhibits tumor necrosis factor- $\alpha$-induced matrix metalloproteinase- 9 expression and cellular invasion by suppressing nuclear factor- $\kappa \mathrm{B}$ activity. BMB Rep. 2015; 48:559-64.

25. Zhou JP, Gao ZL, Zhou ML, He MY, Xu XH, Tao DT, Yang CC, Liu LK. Snail interacts with Id 2 in the regulation of TNF- $\alpha$-induced cancer cell invasion and migration in OSCC. Am J Cancer Res. 2015; 5:1680-91.

26. Dia VP, Pangloli P. Epithelial-to-Mesenchymal Transition in Paclitaxel-Resistant Ovarian Cancer Cells Is Downregulated by Luteolin. J Cell Physiol. 2017; 232:391-401.

27. Baribeau S, Chaudhry P, Parent S, Asselin É. Resveratrol inhibits cisplatin-induced epithelial-to-mesenchymal transition in ovarian cancer cell lines. PLoS One. 2014; 9:e86987.

28. Wu Y, Deng J, Rychahou PG, Qiu S, Evers BM, Zhou BP. Stabilization of snail by NF-kappaB is required for inflammation-induced cell migration and invasion. Cancer Cell. 2009; 15:416-28.

29. Balkwill F. Tumour necrosis factor and cancer. Nat Rev Cancer. 2009; 9:361-71.

30. Pikarsky E, Porat RM, Stein I, Abramovitch R, Amit S, Kasem S, Gutkovich-Pyest E, Urieli-Shoval S, Galun E, Ben-Neriah Y. NF-kappaB functions as a tumour promoter in inflammation-associated cancer. Nature. 2004; 431:461-66.

31. Song GL, Jin CC, Zhao W, Tang Y, Wang YL, Li M, Xiao M, Li X, Li QS, Lin X, Chen WW, Kuang J. Regulation of the RhoA/ROCK/AKT/ $\beta$-catenin pathway by arginine-specific ADP-ribosytransferases 1 promotes migration and epithelial-mesenchymal transition in colon carcinoma. Int J Oncol. 2016; 49:646-56.

32. Jiang Y, Yuan Q, Huang A, Fang Q. The synergistic machanism of pemetrexed followed by Kanglaite was due to KLT subsequently inhibiting the pemetrexed-activated MAPK signaling pathway. Clin Lab. 2015; 61:1353-63.

33. Wong VK, Zhang MM, Zhou H, Lam KY, Chan PL, Law CK, Yue PY, Liu L. Saikosaponin-d Enhances the Anticancer Potency of TNF- $\alpha$ via Overcoming Its Undesirable Response of Activating NF-Kappa B Signalling in Cancer Cells. Evid Based Complement Alternat Med. 2013; 2013:745295. 